\title{
(DES)CONSTRUÇÃO DE MASCULINIDADES DE HOMENS TRANS, ENTRE PORTUGAL E BRASIL
}

Matilde Soares*

Catarina Moreira**

Liliana Rodrigues

Conceição Nogueira

\section{Resumo}

Neste artigo, pretende-se explorar as formas como homens trans (des)constroem as suas masculinidades enquanto lidam com as imposições para aderir à masculinidade hegemónica. Tendo por base o construcionismo social e a teoria queer, procuramos desconstruir modelos dominantes que restringem as suas vivências. Foram entrevistados 12 homens trans, em Portugal e no Brasil, e procedeu-se à análise temática (Braun e Clarke 2006), emergindo cinco temas, dos quais exploramos dois: (i) Negociações com a masculinidade hegemónica; e (ii) Construção de masculinidades alternativas. Estes temas denotam a necessidade de reconhecer a diversidade de formas de "ser homem" e "ser masculino", contribuindo para a promoção de vidas mais livres e espontâneas.

Palavras-chave: Homens trans, masculinidades, masculinidade hegemónica, análise temática.

Centro de Psicologia da Universidade do Porto (CPUP), Faculdade de Psicologia e de Ciências da Educação da Universidade do Porto (FPCEUP).

Endereço postal: Centro de Psicologia da Universidade do Porto, FPCEUP, Rua Alfredo Allen, $\mathrm{s} / \mathrm{n}, 4200-135$ Porto, Portugal.

Endereço eletrónico: matildesoaresbc@hotmail.com

** Centro de Psicologia da Universidade do Porto (CPUP), Faculdade de Psicologia e de Ciências da Educação da Universidade do Porto (FPCEUP).

Endereço postal: Centro de Psicologia da Universidade do Porto, FPCEUP, Rua Alfredo Allen, s/n, 4200-135 Porto, Portugal.

Endereço eletrónico: catarinamrmoreira@outlook.pt

**** Centro de Psicologia da Universidade do Porto (CPUP), Faculdade de Psicologia e de Ciências da Educação da Universidade do Porto (FPCEUP).

Endereço postal: Centro de Psicologia da Universidade do Porto, FPCEUP, Rua Alfredo Allen, s/n, 4200-135 Porto, Portugal.

Endereço eletrónico: frodrigues.liliana@gmail.com

***** Centro de Psicologia da Universidade do Porto (CPUP), Faculdade de Psicologia e de Ciências da Educação da Universidade do Porto (FPCEUP).

Endereço postal: Centro de Psicologia da Universidade do Porto, FPCEUP, Rua Alfredo Allen, s/n, 4200-135 Porto, Portugal.

Endereço eletrónico: cnogueira@fpce.up.pt 


\begin{abstract}
(De)construction of Masculinities of Trans Men, between Portugal and Brazil

The present paper aims to explore the ways in which trans men (de)construct their masculinities while having to deal with the impositions to adhere to hegemonic masculinity. Based on social constructionism and queer theory, we seek to deconstruct dominant models that restrict their experiences. We interviewed 12 trans men, in Portugal and Brazil, and then carried out a thematic analysis (Braun and Clarke 2006). From the five themes that emerged, we focus on two here: (i) Negotiations with hegemonic masculinity; and (ii) Construction of alternative masculinities. These themes denote the need to recognize the multiplicity of ways of "being a man" and "being masculine", contributing to the promotion of freer and more spontaneous lives.
\end{abstract}

Keywords: Trans men, masculinities, hegemonic masculinity, thematic analysis.

\title{
Résumé
}

(Dé)construction de la masculinité des hommes trans, entre le Portugal et le Brésil

Cet article se propose d'explorer la manière dont les hommes trans (dé)construisent leurs masculinités tout en faisant face aux impositions d'une masculinité hégémonique. Ayant pour base le constructionnisme social et une perspective queer, nous avons cherché à déconstruire les modèles dominants qui limitent leurs expériences de vie. Des entretiens individuels ont été menés avec 12 hommes trans, au Portugal et au Brésil, et on a procédé à une analyse thématique (Braun et Clarke 2006), d'où ont émergé 5 thèmes, deux desquelles nous explorons ici: (i) Négociations avec la masculinité hégémonique; (ii) Construction de masculinités alternatives. Ces thèmes révèlent la necessite de reconnaître la diversité de formes $\mathrm{d}^{\prime}$ "«être un homme» et $\mathrm{d}^{\prime}$ "«être masculin», contribuant ainsi à la promotion de vies plus libres et plus spontanées.

Mots clés: Hommes trans, masculinités, masculinité hégémonique, analyse thématique.

\section{Introdução}

Dando-se a oportunidade de acolher as propostas de pensamento lançadas neste número temático, no presente artigo, debruçamo-nos sobre as experiências de homens trans ${ }^{1}$ e as formas como estes (des)constroem as suas masculinidades. Para tal, consideramos como proposta epistémica adequada o recurso às perspetivas do construcionismo social, da teoria queer e do feminismo trans - que, embora não homogéneas, servem de base comum de entendimento para os nossos posicionamentos.

Embora comecem a surgir mais estudos sobre homens trans, estes têm sido negligenciados dentro dos estudos de género, que tendem a ver a masculinidade

Homens trans são pessoas a quem foi atribuído o sexo feminino à nascença e que se identificam como homens, independentemente do desejo ou da realização de mudanças corporais. Neste trabalho, vai ser utilizado o termo "trans" com o objetivo de incluir todas as pessoas cujo género não seja congruente com o que lhes foi designado à nascença, assumindo-se o posicionamento da despatologização e o respeito por qualquer existência quanto ao género. 
como restrita a experiências de homens cis (Oliveira 2014; Catalano 2015; Jourian 2017). Denota-se assim uma falta de visibilidade de homens trans (e demais pessoas masculinas, independentemente da identidade de género), que pode advir de um olhar falocêntrico no que toca ao que é tido como masculino (Almeida 2012).

Existe, na nossa sociedade, a imposição de um binarismo de sexo/género, que apenas reconhece a existência de dois sexos/géneros, e estes como opostos e complementares, determinados biologicamente (Ekins e King 1999). Assim, o sexo é normalmente visto como tendo uma determinante biológica, enquanto o género seria uma construção social, aprendida ao longo da vida (Nogueira 2001). Mesmo estabelecida a distinção, este sistema presume uma congruência entre sexo, género, expressão de género e desejo sexual (Butler 1990; 1999; Louro 2001; Preciado 2019).

Esta matriz é ainda assegurada pela repetição de atos, gestos e símbolos culturalmente estabelecidos, que reforçam a construção de corpos "masculinos" e "femininos". O género pode assim ser visto como performativo, como produtor de significados, permitindo a legitimação desta ordem (Butler 1990). Deste modo, abre-se espaço para a desconstrução de conceções essencialistas e mostra-se como não existe uma natureza feminina ou masculina intrínseca (Butler 1990; Preciado 2019).

Consequentemente, e como qualquer lógica binária e dicotómica, isto resulta na determinação da norma e, assim, na determinação de que vidas e corpos podem ser considerados "existíveis" e legítimos ou, por oposição, ilegítimos e abjetos (Butler 1999; Louro 2001; Oliveira 2014; Preciado 2019). No entanto, esta norma poderia ser subvertida através de um processo de desconstrução que viria questionar os processos através dos quais algumas identidades, mais que outras, são vistas como "normais" (Louro 2001). Deste modo, torna-se necessário desconstruir a obrigatoriedade da "congruência" entre sexo, género e desejo (Butler 1990), possibilitando o reconhecimento de uma maior diversidade e multiplicidade de identidades e expressões de género. Por sua vez, as existências "não-normativas" provam a ineficiência de um modelo binário e cisheteronormativo, ${ }^{2}$ e mostram como este é excludente e discriminador (Oliveira 2014).

Também os discursos biomédicos, apesar de sucessivas mudanças, continuam a basear-se num sistema binário e patologizador, apenas reconhecendo como legítimas pessoas trans que apresentam (ou desejam) uma congruência entre o seu género e o que é tido como o sexo correspondente. Assim, estes discursos continuam a não reconhecer vivências não-normativas como legítimas e a enfatizar uma "normalização" dos corpos dissidentes, através de dispositivos cissexistas (Coll-Planas 2010; Catalano 2015; Rodrigues 2016; Preciado 2019). Esta insistên-

A cisheteronormatividade é a ideologia que determina, através da compulsoriedade, que a "norma" é ser heterossexual e cisgénero, em detrimento de outras existências vistas como abjetas (Mattos e Cidade 2016). 
cia na necessidade de "passar" 3 por normativo perpetua ainda modelos essencialistas e binários do que é ser homem e mulher, de masculinidade e feminilidade (Amâncio 1994; Rodrigues 2016).

Viver dentro de uma estrutura cissexista pressiona sujeitos não-normativos a adaptarem-se ao que é esperado do seu género, uma vez que muitas vezes lhes é negado um estatuto de humanidade: se estes indivíduos não se moldarem aos comportamentos e forma de se apresentarem, então serão deslegitimados (Oliveira 2014). Assim, podem acabar por incorporar, conforme necessário, uma identidade de género que seja reconhecível (Coll-Planas 2010; Rodrigues 2016).

Para serem reconhecidos como homens em sociedade, homens trans podem sentir que têm de corresponder a determinadas exigências: por um lado, teriam de fazer modificações corporais e, por outro, apresentar-se de um modo hegemonicamente masculino (Catalano 2015). Estas pressões podem originar uma necessidade de provar constantemente as suas identidades, através de expressões normativas de género, o que os pode levar a fazer determinadas negociações com a masculinidade hegemónica.

Esta masculinidade - hegemónica - foi descrita por Raewyn Connell (2005) como a configuração atual de práticas de género que legitima a posição dominante dos homens na sociedade, justificando e garantindo a subordinação das mulheres. É esta a forma de masculinidade que se tornou o modelo a seguir e que estabelece padrões a partir dos quais os outros homens são julgados e avaliados - pressionados por uma ideia do que é ser um "homem de verdade" (Marques 2011; Bento 2015).

A masculinidade hegemónica estaria então relacionada com uma busca incansável por ideais de força, sucesso, confiança, competição e dominação, com a glorificação da virilidade (heterossexual e falocêntrica), da violência, da posse e do poder e, ainda, com a desvalorização das mulheres e das feminilidades (Connell 2005; Bento 2015). No entanto, ninguém se encaixa totalmente nestes requisitos, que indicariam inequivocamente que se alcançou o estatuto de ser masculino, pelo que esta ideologia acaba também subordinando todos os homens - tanto os que não conformam com ela quanto os que tentam alcançá-la sem nunca o conseguir (Marques 2011; Bento 2015).

A masculinidade hegemónica é omnipresente na vida de homens trans, o que influencia a forma como constroem e definem a sua própria expressão de género. Alguns parecem resistir a este modelo, questionando e adotando uma perspetiva crítica em relação aos padrões de género; no entanto, há outros que internalizam estes modelos hegemónicos (Jourian 2017). Para muitos homens trans, a única maneira de se sentirem reconhecidos como "homens de verdade" é seguindo e

Com "passar" referimo-nos à "passabilidade", i.e., à não percepção de alguém ser trans, que "passa" por não-trans e/ou cis. 
adotando esses símbolos de uma masculinidade dominante. Porém, reitera-se que esta imposição denota a insistência em apresentar uma identidade reconhecível pelo sistema cissexista e cisnormativo.

Alguns admitem mesmo a adoção de comportamentos compensatórios, que vão ao encontro das expectativas associadas à masculinidade (Jourian 2017). Este aumento de expressões masculinas é geralmente mais observado no início das modificações corporais - quando a passabilidade não é tão grande -, como forma de afirmar a sua identidade. Por oposição, quando o reconhecimento social masculino aumenta, a adesão a performances convencionais de masculinidade diminui (Almeida 2012).

Ainda assim, tanto a presença de indicadores corporais de masculinidade como estas expressões tradicionalmente masculinas continuam a ser tidas como cruciais para a validação de se ser um "verdadeiro" homem no contexto social, o que, por sua vez, contribui para a afirmação das suas identidades (Aboim 2016; Jourian 2017). Assim, a maioria de homens trans tem o desejo de viver e ser percebido como homem, ainda que o ideal de uma masculinidade "normalizada" seja rejeitado (Aboim 2016).

A pressão originada pelos modelos hegemónicos de masculinidade não se nota apenas nos comportamentos e expressões que homens trans adotam ou não, mas também na conciliação com as suas próprias identidades. Segundo Rubin ${ }^{4}$ (2003), a partir de uma comparação com outros homens, e com a preocupação de não serem sexistas e não adotarem uma masculinidade hegemónica, pode-se criar uma barreira para uma identificação despreocupada como homem. No entanto, tem-se notado que para grande parte dos homens trans, a masculinidade não é tida como mandatória para se perceberem como homens, o que lhes permitirá ter uma expressão de género mais livre e fluida, sem sentirem que estão a comprometer a sua identidade de género.

É fundamental, no entanto, reconhecer que estes indivíduos desenvolvem as suas próprias definições de masculinidade enquanto precisam de lidar com as pressões externas da masculinidade hegemónica: homens trans passam por processos de desconstrução e reconstrução, numa renegociação constante das suas identidades (Jourian 2017). Assim, torna-se importante criar pontes entre os estudos trans e os das masculinidades, ampliando a noção de masculinidade, e deixando de a ver a partir de perspetivas essencialistas e redutoras. Com este trabalho, pretendemos então compreender processos de construção de masculinidades, desconstruindo, por um lado, modelos hegemónicos de masculinidade e, por outro, denunciando as imposições da cisnormatividade feitas a corpos de homens trans.

Embora não adotando um posicionamento construcionista, consideramos que Rubin (2003) faz um contributo importante para esta discussão. 


\section{Método}

No presente estudo, pretende-se contribuir para o conhecimento sobre o modo como homens trans constroem e definem as suas masculinidades, procurando compreender qual a influência das imposições da masculinidade dominante nas suas identidades de género e a forma como estes indivíduos lidam com as mesmas. Neste sentido, formularam-se as seguintes questões de investigação: (1) Como é que estes indivíduos concetualizam e vivenciam as suas masculinidades? e (2) Que negociações fazem com a masculinidade hegemónica?

Realizaram-se 12 entrevistas semiestruturadas, 6 em Portugal e 6 no Brasil, entre 2018 e 2020, a pessoas que se autoidentificam como homens trans, com idades compreendidas entre os 18 e os 36 anos. $\mathrm{O}$ acesso aos participantes deu-se inicialmente e paralelamente através da rede de contactos das investigadoras e contactos do ativismo trans e, posteriormente, recorreu-se ao método bola-de-neve.

O procedimento utilizado para a análise dos dados recolhidos foi a análise temática, ${ }^{5}$ segundo as propostas de Braun e Clarke (2006), abordagem esta que se mostra congruente com o quadro teórico sobre o qual se baseia este trabalho, permitindo a análise dos discursos e, assim, realçar as especificidades de cada participante.

\section{Análise e discussão}

Em relação aos objetivos estabelecidos, apresentamos e discutimos alguns dos resultados da análise temática realizada no âmbito de uma dissertação de mestrado. Neste artigo, focamos apenas em dois dos cinco temas que emergiram na totalidade: (i) Negociações com a Masculinidade Hegemónica; e (ii) Construção de Masculinidades Alternativas. Foi ainda possível identificar um organizador central - "Homens de verdade" - segundo o qual se estabeleceram as relações temáticas e que denota o constante confronto entre homens trans e as noções hegemónicas e essencialistas que insistem em definir o que é "ser homem".

\subsection{Negociações com a masculinidade hegemónica}

A partir da análise, percebemos que, em contacto com as pressões que sentem para serem reconhecidos como "homens de verdade", homens trans têm de fazer várias negociações com a masculinidade hegemónica. Como refere Jourian (2017), este tipo de masculinidade é omnipresente, contribuindo, assim, para moldar a

\footnotetext{
Ver a explicitação das fases propostas por Braun e Clarke (2006), aqui apenas nomeadas: familiarização com os dados; produção de códigos iniciais; pesquisa dos temas; revisão dos temas; definição e nomeação dos temas; e produção do relatório final.
} 
forma como homens trans constroem as suas próprias masculinidades, em confronto com estes ideais.

Todos os participantes, num ou noutro ponto de análise (por exemplo, quanto à violência), procuram distanciar-se da masculinidade hegemónica. Assim, emergiram dois códigos - discutidos de seguida - que formam o subtema Rejeição. Muitos referem que se sentem mal consigo mesmos se se aproximam desta forma de masculinidade, surgindo o código Não querer ser "esse tipo de homem". Assim, em concordância com a literatura, muitos homens trans adotam uma perspetiva crítica, questionando este modelo dominante (Jourian 2017). Os participantes rejeitam, então, uma masculinidade hegemónica que procura ter poder sobre "o outro", que é sexista e homofóbica e, ainda, que prega a violência, o controlo e a intimidação - principalmente no que concerne às mulheres com quem se relacionam:

[...] performar uma masculinidade hegemónica e tóxica, baseada na violência, seria a última coisa assim, é algo que eu evito assim, inclusive tipo se eu me vejo agindo de uma maneira próxima disso, eu fico mal mesmo, tipo não é o homem que eu quero ser. (E3BR)

Eu acho que essa situação da masculinidade vem muito por tentar conter as mulheres ali e isso para mim não faz sentido. (E9PT)

Outro aspeto de uma masculinidade dominante que para muitos é questionado é a restrição de emoções. Assim, rejeitam a noção de que "um homem não chora" e não deve expressar sentimentos, entendendo estas características como fazendo parte das vivências de qualquer ser humano e não exclusivamente das feminilidades:

Se queres chorar, choras, sendo mulher ou sendo homem. (...) “um homem não pode chorar, um homem tem de ser duro, um homem tem que ser não sei o quê", não... não tem. Lógico que não tem. (E9PT)

Por outro lado, a rejeição da masculinidade hegemónica pode resultar como um entrave ao reconhecimento e aceitação da identidade masculina por parte destes homens, emergindo o código Masculinidade hegemónica como entrave à identificação. O constante confronto com a noção do que constitui um "homem de verdade", e a consequente rejeição destes ideais, pode resultar no retardamento de uma identificação despreocupada como homem (Rubin 2003). Um participante em particular refere que, por ter, por tanto tempo, identificado traços da masculinidade hegemónica como significantes de "ser homem", não conseguia reconhecer-se como tal. De facto, só a partir da desconstrução destas noções e depois de chegar à conclusão de que não é necessário ser-se sexista para se ser homem e que nem todos os homens são necessariamente sexistas, é que lhe foi possível uma identificação e aceitação da sua identidade sem culpa: 
[...] eu rejeito, e isso foi uma das minhas dificuldades em me assumir, eu rejeito muito a masculinidade hegemónica (...) tinha isso como impeditivo de me assumir e de me aceitar. (E3BR)

Já outro participante teve a sua identificação como homem "atrasada" por não sentir atração por mulheres. Sendo a heterossexualidade referida pelos participantes como uma das características do que constitui um "homem de verdade", homens trans podem sentir que não o são caso tenham outras orientações sexuais. Mais uma vez, foi também através de um processo de desconstrução da heterossexualidade compulsória e do entendimento da possibilidade de existências de homens trans não-heterossexuais que se tornou possível a identificação e a aceitação enquanto homem:

[...] eu tinha aquela ideia bem errónea de que para me identificar como homem trans, (...) eu tinha de passar pela fase de lésbica, (...) eu não entendia como é que eu podia me identificar como homem e não gostar de mulher, e aí foi um processo bem longo e penoso para entender que existiam homens trans que eram gays ou bissexuais. (E4BR)

Embora todos os participantes rejeitem alguns aspetos da masculinidade hegemónica, alguns admitem também a adoção de comportamentos que vão conscientemente ao encontro do que é esperado da masculinidade. Assim, emergiram cinco códigos, abordados de seguida, que compõem o subtema Comportamentos compensatórios - comportamentos estes que têm o propósito de reafirmar masculinidades e garantir o reconhecimento como homens em determinadas situações e contextos (Vegter 2013; Jourian 2017). Assim, grande parte dos participantes recorrem, ou já recorreram, a estes comportamentos com o objetivo de serem aceites enquanto homens, surgindo o código Procura de reconhecimento. Quando sentem ser necessário, homens trans podem fazer-se valer de estratégias (e.g. o uso de binder, ${ }^{6}$ a forma de vestir, de andar e de falar) que garantam que a sua identidade é respeitada:

Eu penso na roupa que vou usar, não saio de casa sem binder, por exemplo (...), nisso eu penso, mas mais por uma questão de evitar maiores constrangimentos assim, de tipo já estar num lugar estranho ao mundo que não me reconhece como um ser masculino e enfim, tentar remediar. (E3BR)

De acordo com a literatura, a análise realizada permitiu também identificar o código Início das mudanças corporais e perceber que estes comportamentos são mais observáveis no início das suas trajetórias enquanto pessoas trans, de forma a afirmar as suas identidades masculinas quando estas não são tão reconhecidas socialUm binder é uma peça de vestuário (ou um tecido) utilizada com o objetivo de encobrir a pre-
sença de mamas e tornar o peito percetivelmente liso. 
mente só por si (Vegter 2013). Isto estaria, então, relacionado com a falta de passabilidade que homens trans têm nessas fases e com o desejo de serem lidos no masculino, quando faltam certos marcadores físicos associados à identidade masculina, como a voz grossa, o peito liso e a barba (Jourian 2017):

[...] talvez no início da transição sim, porque eu cheguei a estimular uma coisa para a sociedade me enxergar como tal (...) até porque tu começa, tu não está com os traços muito masculinos e tal, então tu acaba adotando outras formas de poder representar aquilo que não fisicamente. (E7BR)

[...] no início da minha transição, fazia imenso (...) cada vez que andava na rua, tentar ter um ar masculino e estar assim e sentar-me assim nos transportes [pernas abertas, ocupar mais espaço] tipo sabes aquelas coisas associadas aos homens... (E10PT)

Surgiram ainda várias narrativas que evidenciam a adoção destes comportamentos em situações em que existe uma Perceção de falta de segurança (Abelson 2014). Deste modo, quando se sentem ameaçados, homens trans podem exacerbar as suas expressões de masculinidade, como forma de proteção face a possíveis agressões verbais e/ou físicas:

[...] já tive de andar na rua muitas vezes e fazer cara feia e inflar o peito, porque eu estava em espaços em que (...) a pessoa não podia imaginar quem eu era senão eu estaria em risco. (...) Então tu acaba adotando algumas coisas para se autodefender. (E7BR)

Por último, estes comportamentos são também notados no Convívio com outros homens. Alguns homens trans admitem ter estas preocupações sobre ser "homem suficiente" em situações sociais com homens que tenham masculinidades mais dominantes e adotam comportamentos compensatórios com o propósito de se sentirem aceites:

Talvez um bocado na maneira como interajo com rapazes. (...) coisas que eu nunca faria mas faço só porque pronto, é tipo, é o que se faz. (...) Acho que é mais para ser tipo aceite. (E2PT)

Eu não fazia nada mas pensava sobre isso, tipo (...) demonstrar que eu podia, que nem eles, coisas da vida, tipo "ah eu também sou desejado", (...) “eu também sei jogar futebol", coisas assim. (...) e daí eu via "ai contei esta história na real só porque quero ser aceito". (E3BR)

Finalmente, de acordo com as narrativas obtidas durante as entrevistas, homens trans vão deixando de sentir a necessidade de recorrer a estes comportamentos, surgindo o código Libertação de comportamentos compensatórios. Isto aconteceria quando passam a ter uma maior passabilidade, havendo um reconhecimento social deles enquanto homens sem terem de forçar alguma expressão que o garanta. 
Ao sentirem-se mais seguros e confiantes nas suas identidades e aparências, sem terem de se provar a si ou aos outros, deixam de precisar de recorrer a estas estratégias ou evitar certas expressões tidas como femininas. Assim, como encontrado na literatura, a adesão a performances associadas a uma masculinidade dominante tende a diminuir conforme avançam nos seus processos de mudanças corporais (Almeida 2012; Vegter 2013):

A cirurgia veio-me ajudar muito. (...) foi o que me veio tirar esse peso todo de tentar provar alguma coisa (...) E tudo isso veio fazer com que me sentisse mais confortável e foi-se tornando cada vez mais fácil eu aceitar-me. (E9PT) agora, no ponto da transição em que estou, (...) eu acabo por não ter de provar a minha identidade enquanto homem... que eu antes tinha de fazer, porque não tinha uma passabilidade tão masculina. (E10PT)

Também os participantes que ainda se encontram nestas fases iniciais reconhecem os seus comportamentos compensatórios, mas esperam conseguir libertar-se deles no futuro, logo que o seu reconhecimento social como homens aumente:

[...] eu vejo que hoje, se eu tivesse uma barba (...) e eu quisesse passar um batom para ir numa festa, eu super passaria, não me ia importar, sabe, e eu não faço. (E3BR)

Eu me hormonizo, né, eu penso que em algum momento eu vou me sentir mais confortável para me expressar livremente. (E3BR)

Concluindo, a partir da análise realizada, mostra-se como expressões tradicionalmente masculinas continuam a ser cruciais para a legitimação destes homens como "homens de verdade" - resultados que entram em concordância com estudos anteriores (Vegter 2013; Jourian 2017). Para além disto, mostra-se como o género é performado e concretizado em interações sociais, sendo que homens trans adotam diferentes expressões de género em determinadas situações, numa constante (re)negociação com o que é esperado deles, os seus objetivos e a sua agência. No entanto, estas pressões e expectativas podem resultar na necessidade de se provarem constantemente como "homens de verdade", procurando, assim, (re)afirmar as suas masculinidades persistentemente. Muitas vezes, quando esta afirmação não pode ser feita a partir de símbolos corporais de masculinidade, ainda cruciais para um reconhecimento como seres masculinos (Aboim 2016), homens trans podem acabar por adotar expressões associadas a uma masculinidade hegemónica, passando muitas vezes por contradições consigo mesmos.

\subsection{Construção de masculinidades alternativas}

A partir da análise dos dados recolhidos, notou-se que os homens trans entrevistados concordam com a existência de uma multiplicidade de formas de se ser 
masculino. Não só cada um pode ter a sua própria masculinidade, mas também estas podem ser expressas de formas diferentes em determinados contextos. Assim, ainda que em constante negociação com o que é esperado deles enquanto homens, estes indivíduos tentam construir as suas próprias masculinidades.

Embora "masculinidade" possa ter significados diferentes para cada um deles - algo assumido pelos participantes -, acaba por ser expressa através de comportamentos e preocupações com aspetos semelhantes: formas de vestir, de falar ou de se movimentar. Para estes indivíduos, são estas expressões físicas que os faz sentirem-se masculinos e reconhecidos como tal pelos outros - surgindo o código Desejo de ser reconhecido como homem. Este reconhecimento revela-se significativo, na medida em que contribui para a afirmação das suas identidades e os faz sentirem-se mais seguros e confortáveis consigo mesmos (Aboim 2016):

Claro que quero ser lido enquanto homem na sociedade. (E5BR)

Eu gosto que tenham a perceção de que eu sou um homem, (...) gosto de ser reconhecido como um homem, porque é isso que me faz sentir confortável. (E9PT)

Ainda que algumas das suas expressões possam coincidir com os estereótipos da masculinidade, não o fazem devido a imposições externas, mas por vontade própria. Deste modo, foi possível identificar o código Masculinidade como possibilidade de serem quem são. Assim, as suas masculinidades estariam muito mais relacionadas com a forma como cada um se sente verdadeiro, livre e confortável consigo mesmo, do que com qualquer ideal a que se sintam pressionados a aderir:

É muito mais um feeling de estar bem comigo mesmo e para mim isso é a minha masculinidade (...), é muito aquela coisa construída, de construir a minha masculinidade, de eu olhar assim e me identificar "bom, eu estou bem comigo mesmo". (E5BR)

Eu não me sigo muito pelas normas, mas eu faço o que faz sentido para mim, o que acaba muitas vezes se alinhar com as normas, mas (...) ser masculino para mim é ser aquilo que eu me sinto confortável em ser, é vestir aquilo que eu me sinto confortável, é ter o cabelo que eu me sinto confortável, é usar expressões que fazem sentido para mim e que são naturais para mim, e não ter que estar a esforçar nada... é tipo ser verdadeiro para mim mesmo. (E10PT)

Indo ao encontro da literatura, denota-se que o grande objetivo destes indivíduos é alcançar um lugar de bem-estar consigo mesmos - o que muitas vezes passa por se expressarem de maneiras lidas como masculinas (Nunes 2016). Deste modo, ainda que correspondam a alguns estereótipos de masculinidade, não é esse o foco das suas vivências, mas antes obter um entendimento das suas existências e expressões como sendo autênticas e espontâneas. Acima de tudo, estes homens trans desejam poder ser quem são, adotando expressões que os façam sentir-se verdadeiros para eles próprios. 
Para além disto, a partir da libertação de pressões sentidas sobre o que é ser um "homem de verdade", da desconstrução e rejeição da masculinidade hegemónica, da libertação dos comportamentos compensatórios, e ainda do reconhecimento de privilégios masculinos, parece dar-se uma construção de masculinidades alternativas, livres e espontâneas, que procuram ser mais justas e igualitárias. Deste modo, emergiram quatro códigos - discutidos de seguida - que deram origem ao subtema (Des)construção. Primeiramente, identificamos o código Construção através da desconstrução - um processo constante de reconstrução de masculinidades por parte de homens trans (Jourian 2017), através do qual estes se (des)constroem conscientemente, sempre em questionamento sobre que tipo de homem desejam ser:

Eu estou construindo a minha masculinidade, que eu acho que é uma masculinidade interessante. É uma construção que passa primeiro por uma... desconstruir para depois, aos pouquinhos, ir construindo algo. (...) Até para tu quebrar a regra tu tem que saber qual é a regra. (E7BR)

[...] tu na verdade é uma eterna desconstrução para formar alguma coisa. (...) porque não adiantaria de nada passar por tudo o que eu passei e aí tá, mas que tipo de homem eu devo ser? (...) E aí, então é uma construção que na verdade só veio com a desconstrução de muita coisa. (E8BR)

Através da análise, surgiu também o código Noção de privilégios como fator decisivo - isto é, para alguns homens trans, o desejo de construírem masculinidades mais igualitárias pode emergir do reconhecimento de privilégios masculinos. Ao serem confrontados com uma mudança - por vezes drástica - na forma como são tratados a partir do momento em que são reconhecidos como homens, sentem-se muitas vezes responsáveis por não perpetuar comportamentos e atitudes sexistas de que eles próprios foram vítimas. Assim, é pelas suas vivências e trajetórias enquanto pessoas trans que alguns dos participantes sentem que têm uma maior predisposição para rejeitar comportamentos preconceituosos e discriminantes e, consequentemente, para desejar construir masculinidades mais "justas":

[...] é o mínimo que eu posso fazer num contexto que me privilegia, (...) o dever de colocar reflexões pontuais (...) e eu me sinto extremamente responsável por isso. (...) porque para mim foram essenciais para a construção da ideia do tipo de homem que eu gostaria de ser. (E8BR)

Talvez a gente tenha uma sensibilidade maior porque talvez a gente estava do outro lado, passou muitas opressões, então para nós acaba sendo mais visceral. (E7BR)

Muitos - principalmente os que têm trajetórias informadas pelo ativismo referem ainda o desejo de se sentirem livres de categorias impostas de género, surgindo o código Críticas ao sistema binário de género. Deste modo, questionam e 
problematizam também a compulsoriedade de uma normatividade cisgénera imposta às suas vivências e corpos. Por oposição, defendem a desconstrução destas categorias essencialistas e a criação de novos paradigmas acerca do que é ser homem e do que é ser masculino. Com isto, pretendem a possibilidade de existências mais livres e espontâneas:

[...] chega dessas categorias biomédicas, chega dessas coisas culturais (...) conservadoras, fechadas, preconceituosas, discriminantes. Então vamos construir, vamos discutir as masculinidades, o que é ser homem, (...) e vamos pegar e criar novos paradigmas. (E5BR)

[...] as pessoas reprimem muitas partes da sua identidade que, se calhar noutro contexto, se sentiriam muito mais livres a exprimir e seriam pessoas com muita mais abertura, e muito mais felizes, e muito mais espontâneas, e que não teriam medo de sentir repercussões pelos seus comportamentos que com esta imposição de binarismo de género, acabam por não sentir. (E10PT)

Foi possível ainda identificar o código Subversão das normas. Estes mesmos indivíduos, ativistas, não pretendem apenas subverter as categorias binárias de género, como se assumem como a própria transgressão face às mesmas. Assim, a existência de corpos trans pode ser vista como desafiadora de toda e qualquer hegemonia (Oliveira 2014). Os homens trans que adotam esta posição são, assim, consciente e orgulhosamente anti-sistema, revolucionários, transgressores, queer ${ }^{7} \mathrm{e}$ incomodativos numa sociedade que se quer dentro das normas:

Eu sou, por natureza, um transgressor (...) me identificando como uma pessoa trans. (E7BR)

[...] ao identificar-me como pessoa trans já quebrei imensas regras (...) e sinto que (...) nem é tanto ir contra essas regras, é mais destruir essas regras, fazer com que elas não existam. (E10PT)

Eu quero incomodar, eu quero gritar. (...) Acho que a ideia é fazer as pessoas pensarem, é provocar mesmo. (...) Só o facto de incomodar já está muito bom. (E5BR)

Como conclusão, estes processos continuados de desconstrução podem resultar na construção de "novas" masculinidades que rompem com os modelos hegemónicos de masculinidade: estes sujeitos parecem ocupar um lugar "privilegiado" para criar masculinidades não violentas, mas antes saudáveis, empáticas,

Queer pode ser traduzido por "estranho", "esquisito" ou "ridículo". Termo usado de modo pejorativo, que atribuiria um lugar abjeto àqueles a quem é dirigido (Butler 1999; Louro 2001). Foi depois reapropriado por parte dos movimentos LGBT, que o ressignificaram como forma de se posicionar contra a heteronormatividade (Preciado 2019). Queer passa a representar a diferença que não quer ser assimilada nem mesmo apenas tolerada (Louro 2001). 
sensíveis e funcionais - contribuindo, deste modo, para uma sociedade mais justa e igualitária. Assim, identificamos um último código - Masculinidades trans como alternativa à masculinidade hegemónica -, que mostra como estas masculinidades podem então ter potencial para gerar uma mudança de paradigma, ao mostrar alternativas a uma masculinidade hegemónica, dominante e essencialista:

Eu vejo nas transmasculinidades a possibilidade de quebrar com a masculinidade hegemónica e construir novas masculinidades saudáveis, funcionais, para uma sociedade igualitária. (E3BR)

O que é para mim ser homem? (...) não sei a resposta, acho que nunca vou saber (...) estou aprendendo a criar uma masculinidade que a mim me agrada, onde eu não sou violento com as pessoas e, enfim, não reproduzo essas violências. (E7BR)

[...] é isso que faz ser quem eu sou, é isso que promove a construção do tipo de homem que eu quero ser, (...) eu acho que é agir na contramão, tentar também construir masculinidades menos tóxicas, acho que é isso. (E8BR)

Assim, evidencia-se a necessidade de discutir, questionar e desconstruir o que é "a masculinidade", não apenas de uma perspetiva identitária, mas entendendo as relações de género como cruciais para a possibilidade de uma sociedade mais justa (Connell 2005):

É importante não trabalhar apenas as feminilidades, mas questionar a masculinidade também, porque ela é tóxica, não só para as mulheres, mas para os próprios homens que vivenciam isso e são afetados por isso. (E5BR)

\section{Conclusão}

Este artigo pretendeu explorar as formas como homens trans constroem as suas masculinidades, enquanto têm de lidar simultaneamente com as imposições para aderir à masculinidade hegemónica. A partir da análise, percebemos que expressões associadas a uma masculinidade dominante continuam a ser fundamentais para a obtenção de reconhecimento social e legitimação destes homens. Assim, ainda que rejeitem estes modelos, muitos acabam por adotar comportamentos que lhes permitam ver as suas identidades validadas, (re)negociando-as constantemente. Por outro lado, podem também ser algumas das expressões que se assemelham a traços desta masculinidade que os fazem sentir-se "verdadeiros consigo próprios".

No entanto, grande parte dos participantes procura (re)construir masculinidades mais livres e igualitárias, através da desconstrução e da rejeição de modelos hegemónicos - homens trans parecem ter uma maior propensão para criar masculinidades não violentas mas empáticas, que contribuam para uma sociedade mais 
justa de relações de género. As masculinidades trans podem, então, apresentar alternativas à masculinidade hegemónica. Não se pretende, com isto, transmitir uma ideia homogénea das masculinidades trans, mas antes assumi-las como possíveis potenciadoras de mudança. De facto, homens trans passam por várias contradições, não sendo necessária e totalmente normativos nem tampouco subversivos ou contrahegemónicos. No entanto, vê-se nas masculinidades construídas por estes indivíduos uma oportunidade para ressignificar o que é ser homem e masculino.

Torna-se necessário, assim, promover um questionamento sobre estas categorias, desmantelar a ideia de "homem de verdade" e problematizar modelos dominantes, discutindo e evidenciando a multiplicidade de formas de construção de masculinidades. Para além disto, denotamos que a masculinidade hegemónica é prejudicial para todos e todas, tanto por perpetuar a submissão de mulheres como por submeter os próprios homens a estes requisitos restritivos de liberdades (Connell 2005; Bento 2015).

Com isto, mostra-se imprescindível discutir as masculinidades, revelando as imposições a que homens trans estão sujeitos e as performances a que muitas vezes têm de aderir para serem legitimados e respeitados como homens em sociedade. Ainda que queiram (ou não) romper com as normas, ao viver numa estrutura binária, muitas vezes torna-se necessário utilizar uma apresentação normativa de forma estratégica. No entanto, é importante reconhecê-los como agentes das suas próprias vidas, capazes de fazer escolhas políticas e críticas que contribuam para um mundo mais justo socialmente.

Enquanto psicólogos/as que fazem investigação sobre identidades trans, é também fundamental priorizar uma busca de conhecimento em co-construção e implicado com as vivências destas pessoas. Quanto a limitações e a investigações futuras, parece essencial valorizar uma perspetiva intersecional - tendo em conta marcadores sociais como a idade, a raça/etnia, a autoidentificação e a localização - de modo a alcançar um conhecimento mais aprofundado sobre as masculinidades trans e a forma como diferentes pertenças identitárias influenciam as vivências de homens trans.

Em suma, pretende-se visibilizar alternativas aos sistemas opressivos que moldam as vivências de homens trans, e que, no fundo, controlam e restringem a diversidade humana. É necessário, então, um maior e mais inclusivo reconhecimento de identidades trans e de formas de "ser homem" e/ou masculino, sem as negar ou oprimir.

\section{Referências bibliográficas}

Abelson, Miriam J. 2014. "Dangerous privilege: Trans men, masculinities, and changing perceptions of safety." Sociological Forum 29 (3):549-570. DOI: https: / / doi.org/10.1111/ socf.12103 
Aboim, Sofia. 2016. "Trans-masculinities, embodiments and the materiality of gender: Bridging the gap." NORMA 11 (4): 225-236. DOI: https:/ / doi.org/10.1080/18902138. 2016.1259848

Almeida, Guilherme. 2012. "'Homens trans': novos matizes na aquarela das masculinidades?" Revista Estudos Feministas 20 (2): 513-523. DOI: https: / / doi.org/10.1590/S0104026X2012000200012

Amâncio, Lígia. 1994. Masculino e feminino. A construção social da diferença. Porto: Afrontamento.

Bento, Berenice. 2015. Homem não tece a dor: queixas e perplexidades masculinas. (2a ed.). Natal, RN: EDUFRN.

Braun, Virginia, e Victoria Clarke. 2006. "Using thematic analysis in psychology." Qualitative Research in Psychology 3 (2): 77-101. DOI: 10.1191/1478088706qp063oa

Butler, Judith. 1990. Gender Trouble: Feminism and the Subversion of Identity. New York, NY: Routledge.

Butler, Judith. 1999. "Corpos que pesam: sobre os limites discursivos do 'sexo'." In O corpo educado: pedagogias da sexualidade, editado por Guacira Lopes Louro. Belo Horizonte: Autêntica.

Catalano, D. Chase James. 2015. “'Trans enough?' The pressures trans men negotiate in higher education." Transgender Studies Quarterly 2 (3): 411-430. DOI: https: / / doi.org/ $10.1215 / 23289252-2926399$

Coll-Planas, Gerard. 2010. "Introducción." In El género desordenado: Críticas en torno a la patologización de la transexualidad, editado por Miquel Missé e Gerard Coll-Planas, 15-25. Barcelona: Egales.

Connell, Raewyn. W. 2005. Masculinities ( $2^{\text {nd }}$ ed.). Cambridge: Polity Press

Ekins, Richard, e Dave King. 1999. "Towards a sociology of transgendered bodies." The Sociological Review 47(3): 580-602. DOI: https: / / doi.org/10.1111/1467-954X.00185

Jourian, T. J. 2017. "Trans* forming college masculinities: Carving out trans* masculine pathways through the threshold of dominance." International Journal of Qualitative Studies in Education 30(3): 245-265. DOI: https: / / doi.org / 10.1080/09518398.2016.1257 752

Louro, Guacira Lopes. 2001. "Teoria queer - uma política pós-identitária para a educação." Revista Estudos Feministas 9(2): 541-553. DOI: http: / / dx.doi.org/10.1590/ S0104-026X 2001000200012

Marques, António Manuel. 2011. Masculinidade e profissões: discursos e resistências. Lisboa: Fundação Calouste Gulbenkian e FCT.

Mattos, Amana Rocha, e Maria Luiza Rovaris Cidade. 2016. "Para pensar a cisheteronormatividade na psicologia: lições tomadas do transfeminismo." Revista Periódicus 1(5): 132-153.

Nogueira, Conceição. 2001. "Feminismo e discurso do gênero na psicologia social." Psicologia E Sociedade: Revista da Associação Brasileira de Psicologia Social 13(1): 107-128. DOI: http: / / hdl.handle.net/1822/4117

Nunes, Luís Romano. 2016. “Metamorfoses: identidades e papéis de género. Um estudo com Transhomens." Dissertação de mestrado, Universidade de Évora.

Oliveira, André Lucas. 2014. “Os homens transexuais brasileiros e o discurso pela (des) patologização da transexualidade." In Transfeminismo: Teorias e Práticas, editado por Jaqueline Gomes de Jesus, 87-105. Rio de Janeiro: Metanoia Editora.

Preciado, Paul B. 2019. Manifesto Contra-Sexual. Lisboa: Orfeu Negro.

Rodrigues, Liliana. 2016. "Viagens trans(género) em Portugal e no Brasil: uma aproximação psicológica feminista crítica." Tese de doutoramento, Universidade do Porto. 
Rubin, Henry. 2003. Self-made Men: Identity and Embodiment Among Transsexual Men. Nashville, TN: Vanderbilt University Press.

Vegter, Vanessa. 2013. “Conceptualizing Masculinity in Female-to-Male Trans-identified Individuals: A Qualitative Inquiry." Canadian Journal of Counselling and Psychotherapy/ Revue canadienne de counseling et de psychothérapie 47(1): 88-108.

Matilde Soares. Mestre em Psicologia do Comportamento Desviante e da Justiça pela Universidade do Porto (FPCEUP). No âmbito da dissertação de mestrado, desenvolveu, entre Portugal e Brasil, o estudo qualitativo "'Homens de verdade': (des)construção de masculinidades de homens trans". As suas áreas de interesse e produção científica focam-se nos estudos de género e sexualidades não normativas.

Endereço eletrónico: matildesoaresbc@hotmail.com

Catarina Moreira. Mestre em Psicologia Clínica e da Saúde pela Universidade do Porto (FPCEUP). No âmbito da dissertação de mestrado, desenvolveu o estudo qualitativo "A caminho da aceitação... Vivências de mães e pais face à identidade de género dos/as filhos/as não conforme o sexo". Paralelamente à investigação, integra a equipa da Casa Qui - Associação de Solidariedade Social enquanto psicóloga clínica. As suas áreas temáticas de interesse e produção científica são género, sexualidades e LGBTI. Endereço eletrónico: catarinamrmoreira@outlook.pt

Liliana Rodrigues. Investigadora Integrada do Centro de Psicologia da Universidade do Porto. Doutora em Psicologia pela FPCEUP; Mestre em Psicologia da Justiça e Licenciada em Psicologia pela Universidade do Minho. No âmbito do seu doutoramento foi bolseira da FCT, desenvolvendo a tese "Viagens trans(género) em Portugal e no Brasil: uma aproximação psicológica feminista crítica". As suas áreas de interesse e produção científica centram-se nos estudos de género e sexualidades não normativas.

Endereço eletrónico: frodrigues.liliana@gmail.com

Conceição Nogueira. Professora Associada com Agregação da FPCE da Universidade do Porto. Doutora em Psicologia Social pela Universidade do Minho. Autora de inúmeras publicações nacionais e internacionais - revistas, livros, capítulos de livro, atas de congressos - sobre Estudos de Género, Feminismos e Sexualidades. Coordenadora/investigadora principal de diversos projetos de investigação com financiamento e apoio da CIG, da FCT e do Fundo Social Europeu nos domínios em que é especialista.

Endereço eletrónico: cnogueira@fpce.up.pt

Artigo recebido a 04 de janeiro e aceite para publicação a 17 de maio de 2021. 